\title{
Utilization of preventive care services and their effect on cardiovascular outcomes in the United States
}

\section{Varun Vaidya \\ Gautam Partha \\ Jennifer Howe}

Pharmacy Health Care Administration, Department of Pharmacy Practice, University of Toledo College of Pharmacy, Toledo, OH, USA
Correspondence: Varun Vaidya Pharmacy Health Care Administration, Department of Pharmacy Practice, University of Toledo College of Pharmacy, Health Science Campus, 3000 Arlington Avenue, Toledo, $\mathrm{OH} 43614$, USA

Tel +l 419383 I5I6

Email varun.vaidya@utoledo.edu
This article was published in the following Dove Press journal:

Risk Management and Healthcare Policy

I8 January 201 I

Number of times this article has been viewed

Objective: To describe and analyze utilization of preventive care services and their effect on cardiovascular outcomes in the United States.

Methods: Data from the 2007 Medical Expenditure Panel Survey (MEPS) were used to analyze utilization of preventive care services and their effect on cardiovascular outcomes. Recommendations by the Seventh Report of the Joint Committee on Prevention, Detection, Evaluation and Treatment of High Blood Pressure and the National Cholesterol Education Program were used to determine appropriate levels of preventive care utilization. Utilization of blood pressure screening and cholesterol checkup services were used as the dependent variable, while age, gender, race, ethnicity, insurance status, and perceived health status were used as independent variables. Since guidelines differ for people with elevated blood pressure, respondents with elevated blood pressure were identified in the MEPS database by self-reported diagnosis. Descriptive statistics were used to describe the population, while a multivariate logistic regression model was built to predict odds of utilizing appropriate levels of preventive services.

Results: Total number of adult respondents for which data were available for blood pressure checkup and cholesterol checkup was 20,523 and 15,784, respectively. Overall, MEPS respondents were found to adhere to guideline recommendations for preventive care utilization. Multivariate logistic regression showed that odds of utilization of preventive care services were higher for elderly patients (age $>65$ years) for blood pressure (odds ratio $[\mathrm{OR}]=2.39,95 \%$ confidence interval [CI]: $1.92-2.97)$ and cholesterol (OR $=3.05,95 \% \mathrm{CI}: 2.18-4.27)$ preventive services compared with younger population (age 18-54 years). Males had much lower odds of getting blood pressure $(\mathrm{OR}=0.33,95 \% \mathrm{CI}$ : $0.30-0.37)$ and cholesterol $(\mathrm{OR}=0.59,95 \% \mathrm{CI}$ : $0.50-0.70$ ) checks done compared with females. Odds of utilization were nearly similar for all races. Uninsured had lower odds for blood pressure (OR $=0.26,95 \% \mathrm{CI}: 0.23-0.30)$ and cholesterol $(\mathrm{OR}=0.30,95 \% \mathrm{CI}: 0.24-0.39)$ checks compared with privately insured people. Asians had lower odds of getting blood pressure checkups compared to Whites (OR $=0.49,95 \%$ CI: 0.39-0.63). Similar trends were recorded for other covariates such as race and perceived health status.

Conclusion: The study was successful in identifying existing age, race, income, and insurancestatus related disparities in preventive care utilization within a US population.

Keywords: guidelines, prevention/screening, gender differences in health and health care, racial/ethnic differences in health and health care

\section{Introduction}

The current health status of the United States reflects inadequacies in the delivery and consumption of health care, especially when it comes to the use of preventive care services. ${ }^{1}$ Preventive care services encompass a variety of health care measures, 
including immunizations, disease screenings, and behavioral counseling, with the purpose of preventing the occurrence of chronic disease and detecting disease early. ${ }^{1}$ It has been shown that preventive care service utilization improves quality of life and reduces premature mortality. ${ }^{2,3}$ According to Mokdad et al, the leading causes of death in 2000 were heart disease, malignant neoplasm, and cerebrovascular disease, all of which can be attributed to modifiable behavioral risk factors. ${ }^{4}$ Specifically, cardiovascular disease accounted for $34.3 \%$ of all deaths in the United States, while remaining one of the leading causes for mortality in the developing world. 5,6 In addition, cardiovascular diseases also pose a significant economic burden, amounting to US\$403.1 billion, according to a 2006 estimate. $^{7}$

While preventive measures can be costly, they are proposed to lower overall health care expenditures over time by addressing potential health problems sooner rather than later. $^{2}$ It has been estimated that by preventing cardiovascular diseases, the economic health burden would decline by nearly $17 \%$, which translates to US $\$ 149$ billion. ${ }^{8}$ Besides trying to reduce cardiovascular risk factors such as tobacco use, poor diet, physical inactivity, and alcohol consumption, regular blood pressure checkups and cholesterol screenings have been identified as useful preventive care services. ${ }^{9}$ Blood pressure and cholesterol screenings are quick and simple and can aid in the timely diagnosis of hypertension and hyperlipidemia. ${ }^{10}$ Healthy People 2010 has identified the usefulness of these screenings and, as a result, aims to increase their utilization among the eligible United States population. ${ }^{3}$ However, despite the goals put forth by Healthy People 2010, the United States population is still not adhering appropriately to guidelines for blood pressure and cholesterol screenings. ${ }^{11}$ Several factors have been identified that may provide explanations for the underuse of these screenings. The absence of health insurance hinders utilization due to high out-of-pocket costs of preventive services for vulnerable individuals. ${ }^{1}$ In a recent study examining continuity and receipt of diabetes preventive care, those who were continuously uninsured were less likely to utilize important preventive care services such as cholesterol screening. ${ }^{12}$ Ethnicity-related differences have also been observed, with non-Hispanics reporting more frequent use of preventive care screenings than Hispanics. ${ }^{13}$ Lack of awareness of cardiovascular screening guidelines or perception of good health may also be factors that prevent eligible individuals from seeking these services. ${ }^{1}$ Therefore, it is apparent that the use of health care services seems to vary according to different factors such as gender, race/ethnicity, and insurance status.
The existing literature on preventive care tends to focus on utilization among individuals already diagnosed with specific disease states such as diabetes. ${ }^{12,13}$ However, since preventive care utilization recommendations are intended for all eligible individuals, it would seem more appropriate to apply a broader view on the use of preventive care services among healthy, disease-free individuals. The purpose of this study was to analyze and predict trends in the utilization of preventive care services among eligible individuals in the United States. Findings from this study will assist in identifying subpopulations that are not utilizing preventive care services adequately, thereby increasing their risk for developing chronic conditions. Taking a broad approach through predicting the use of preventive care services for all eligible individuals will draw the attention of policymakers towards individuals less likely to use health promotion and prevention services, and thus enable strict reinforcement of cardiovascular health care recommendations.

\section{Methods}

\section{Study design and data source}

The study used a retrospective, cross-sectional research design. The data source utilized was the 2007 Medical Expenditure Panel Survey (MEPS). MEPS is a nationally representative sample of the noninstitutionalized, civilian United States population in which individuals are interviewed five times over a 2-year period. National estimates on health care use, expenditures, and insurance coverage can be determined using this database. Due to the panel design of the survey, the 2007 dataset contained a year's worth of data after pooling respondents from two panels, one of which was completing all the interview rounds and the other was being initiated.

\section{Inclusion criteria}

For the purpose of identifying appropriate utilization of preventive care services that impact cardiovascular outcomes, the recommendations of existing guidelines were used. The National Cholesterol Education Program (NCEP) and the Seventh Report of the Joint Committee on Prevention, Detection, Evaluation and Treatment of High Blood Pressure (JNC-VII) are widely accepted guidelines that have recommendations on who should utilize the preventive care services and the frequency with which these services need to be utilized. ${ }^{14,15}$ NCEP guidelines state that adults over the age of 20 years should have their cholesterol checked once every 5 years, with a full lipid profile performed. Respondents to the survey who reported a cholesterol checkup within 
5 years were thus identified as adherent to the guidelines. JNC-VII gives recommendations for adults based on their blood pressure readings. Adults who are normotensive, ie, a systolic blood pressure of less than or equal to 120 and diastolic blood pressure of less than or equal to 80 , are recommended to have their blood pressure checked at least once every 2 years. On the other hand, adults who have elevated blood pressure levels are recommended to have their blood pressure checked once every year. Our analysis to determine appropriate utilization was therefore restricted to respondents over the age of 20 years for cholesterol checkup utilization and respondents over the age of 18 years for blood pressure checkup utilization. Amongst these individuals, survey respondents who responded to the questions about when they had their last blood pressure/cholesterol checkups were included in the study.

\section{Dependent and independent variables}

Appropriate utilization of preventive care service, as per national guidelines, was used as a dependent variable. For the cholesterol checkup utilization, respondents needed to have had their cholesterol checked within the last 5 years to be termed utilizers. Respondents with elevated blood pressure must have had their blood pressure checked within the last year to be classified as utilizers, while normotensive respondents required a blood pressure check within the last 2 years to be termed as utilizers. Individuals with elevated blood pressure were identified by their responses to the question, "Other than during pregnancy, have you ever been told by a doctor or other health professional that you had hypertension, also called high blood pressure"?

Age, gender, race, ethnicity, insurance status, income level, and perceived health status were used as independent variables because of evidence of their link to utilization of health services. Race was broken down as classified in MEPS into White, Black, Alaskan Indian, Asian, Native Hawaiian, and multiple races. Insurance status of the respondents was identified from the survey; respondents were classified as uninsured, having public insurance, or having private insurance. Income level was stratified into categories as follows: <US\$20,000; US\$20,000-\$34,999; US\$35,000-\$54,999; and >US\$55,000. Perceived health status was reported by the respondents as excellent, very good, good, fair, or poor.

\section{Statistics}

Descriptive statistics were used to describe the population. A multivariate logistic regression model was built to predict odds of utilizing appropriate preventive services using aforementioned independent variables as the predictors. To obtain unbiased national estimates, the Agency for Healthcare Research and Quality has formulated weights to adjust for the complex survey design. The sampling weights are also useful in adjusting nonresponse bias to estimate population totals on the basis of United States census data. The SAS statistical package (SAS Institute, Cary, NC) was used to accommodate the complex sample design and weighting and for data analysis.

\section{Results}

The total of unweighted survey respondents for the 2007 MEPS data was 30,964. After restricting the sample to respondents meeting the inclusion criteria for each of the dependent variables, 20,523 respondents were included for analysis for blood pressure checkup utilization and 15,784 respondents for cholesterol checkup utilization. For blood pressure checkup utilization, the majority of the respondents were female $(51.68 \%)$, White $(81.6 \%)$, privately insured $(69.7 \%)$, and perceived their health status to be very good (32.5\%). Respondents for cholesterol checkup utilization were also primarily female $(53.6 \%)$, White $(82.0 \%)$, privately insured $(73.0 \%)$, and perceived their health status to be very good (32.5\%). The demographic breakdown for the population is represented in Table 1.

Utilization of blood pressure checkup was high for both variables that were the focus of our study. Blood pressure checkup guidelines were followed by $87.5 \%(n=17,959)$ of the study population, and cholesterol checkup guidelines were followed by $94.7 \%(n=14,956)$ of the study population. Multivariate logistic regression showed that odds of utilization of preventive care services varied depending on independent variables. Compared with the younger population (age 18-54 years), elderly patients (age $>65$ years) had much higher odds of using the blood pressure (odds ratio $[\mathrm{OR}]=2.40,95 \%$ confidence interval $[\mathrm{CI}]: 1.77-3.25)$ and cholesterol $(\mathrm{OR}=3.05,95 \% \mathrm{CI}: 2.18-4.26)$ preventive services. Males had much lower odds of getting blood pressure $(\mathrm{OR}=0.33,95 \% \mathrm{CI}: 0.30-0.37)$ and cholesterol $(\mathrm{OR}=0.59$, 95\% CI: 0.50-0.70) checks compared with females. Odds of utilization were nearly similar for all races for cholesterol checkup, but Asians had lower odds of getting blood pressure checkups compared to Whites (OR $=0.49,95 \%$ CI: 0.39-0.63). Uninsured respondents had lower odds for completing blood pressure $(\mathrm{OR}=0.26,95 \% \mathrm{CI}$ : $0.23-0.30)$ and cholesterol (OR $=0.30,95 \%$ CI: $0.24-0.39)$ checkups compared with privately insured people. A trend of increased 
Table I Sample distribution

\begin{tabular}{|c|c|c|c|c|}
\hline \multirow[t]{2}{*}{ Variable } & \multicolumn{2}{|c|}{ Blood pressure check } & \multicolumn{2}{|c|}{ Cholesterol checkup } \\
\hline & $\begin{array}{l}\text { Unweighted } \\
\text { frequency }\end{array}$ & $\begin{array}{l}\text { Weighted } \\
\text { percentage }^{a}\end{array}$ & $\begin{array}{l}\text { Unweighted } \\
\text { frequency }\end{array}$ & $\begin{array}{l}\text { Weighted } \\
\text { percentage }^{a}\end{array}$ \\
\hline \multicolumn{5}{|l|}{ Age } \\
\hline $18-54$ & 13,578 & 68.79 & 9210 & 61.20 \\
\hline $55-64$ & 2504 & 13.22 & 2350 & 16.26 \\
\hline$>65$ & 3466 & 17.99 & 3319 & 22.54 \\
\hline \multicolumn{5}{|l|}{ Gender } \\
\hline Male & 9388 & 48.32 & 6960 & 46.36 \\
\hline Female & 11,135 & 51.68 & 8824 & 53.64 \\
\hline \multicolumn{5}{|l|}{ Race } \\
\hline White & 15,628 & 81.55 & 12,013 & 82.04 \\
\hline Black & 3321 & 11.47 & 2576 & 11.28 \\
\hline American Indian/Alaska Native & 161 & 0.76 & 112 & $0.7 \mid$ \\
\hline Asian & 1036 & 4.56 & 813 & 4.46 \\
\hline Non-Hawaiian/Pacific Islander & 74 & 0.31 & 55 & 0.28 \\
\hline Multiple races & 303 & 1.34 & 215 & 1.22 \\
\hline \multicolumn{5}{|l|}{ Ethnicity } \\
\hline Hispanic & 4597 & $|3.4|$ & 3195 & 11.93 \\
\hline Non-Hispanic & 15,926 & 86.59 & 12,589 & 88.07 \\
\hline \multicolumn{5}{|l|}{ Insurance } \\
\hline Private & 12,622 & 69.71 & 10,230 & 73.03 \\
\hline Public & 4059 & 15.29 & 3248 & 16.02 \\
\hline Uninsured & 3842 & 15.00 & 2306 & 10.95 \\
\hline \multicolumn{5}{|l|}{ Income (US\$) } \\
\hline$<20,000$ & 9664 & 40.17 & 6785 & 35.55 \\
\hline $20,000-34,999$ & 4250 & 21.66 & 3281 & 21.27 \\
\hline $35,000-54,999$ & 3189 & 18.80 & 2698 & 20.68 \\
\hline$>55,000$ & 3084 & 19.37 & 2778 & 22.50 \\
\hline \multicolumn{5}{|l|}{ Perceived health status } \\
\hline Excellent & 4795 & 26.29 & 3414 & 24.28 \\
\hline Very good & 6179 & 32.54 & 4720 & 32.48 \\
\hline Good & 5820 & 27.38 & 4551 & 27.93 \\
\hline Fair & 2513 & 10.36 & 2133 & $|1.5|$ \\
\hline Poor & 851 & 3.41 & 756 & 3.80 \\
\hline
\end{tabular}

Note: 'Weighted percentages have been obtained after adding weights to account for the complex design of the Medical Expenditure Panel Survey.

utilization of preventive care service was seen with decreases in perceived health status. Highest odds of utilization were seen amongst respondents who perceived their health status as poor in both blood pressure $(\mathrm{OR}=3.65,95 \% \mathrm{CI}$ : 2.57-5.20) and cholesterol (OR $=3.08,95 \% \mathrm{CI}: 1.60-5.95)$ respondent groups. Results of logistic regression can be seen in Table 2.

\section{Discussion}

Overall, results from our study show that the utilization patterns for blood pressure checkup were on par with the most recent national statistics from 2003. On the other hand, the utilization of the cholesterol checkup was found to be higher compared with the available national statistics. ${ }^{16}$ While improvement in utilization of cholesterol screenings in the 4 years since the last available statistic is a good sign, the lack of improvement in the size of the population utilizing blood pressure checkup is a cause for concern. A multivariate logistic regression model revealed vulnerable populations amongst our study group. Underutilization of the preventive care services was found to occur amongst the younger population, the age group from 18 to 54 years of age. Lack of utilization of health care services, including preventive care services, has been noticed before in this age bracket, especially among the younger adults. ${ }^{17}$ Some common reasons for underutilization amongst this population are lack of access to care, absence of health insurance, and often a lower self-perceived risk. ${ }^{18}$ Special attention is therefore warranted for this population as elevated blood pressure and high cholesterol levels usually go undetected and have substantial deleterious effects on health with increasing age, if left untreated. ${ }^{19}$ Early diagnosis can prompt early treatment and prevent further development of complications. On the other end of the age spectrum, older individuals were more 
Table 2 Multivariate logistic regression results

\begin{tabular}{|c|c|c|c|c|c|c|c|}
\hline \multirow[t]{2}{*}{ Variable } & \multirow{2}{*}{$\begin{array}{l}\text { Reference } \\
\text { category }\end{array}$} & \multicolumn{3}{|c|}{ Cholesterol checkup $^{a}$} & \multicolumn{3}{|c|}{ Blood pressure checkup ${ }^{b}$} \\
\hline & & \multirow{2}{*}{$\begin{array}{l}\text { Odds } \\
\text { ratio }\end{array}$} & \multicolumn{2}{|c|}{ Confidence limit } & \multirow{2}{*}{$\begin{array}{l}\text { Odds } \\
\text { ratio }\end{array}$} & \multicolumn{2}{|c|}{ Confidence limit } \\
\hline \multicolumn{6}{|l|}{ Age } & & \\
\hline $55-64$ & $18-54$ & $2.40^{c}$ & 1.77 & 3.25 & $1.40^{\mathrm{d}}$ & 1.15 & I.7। \\
\hline$>65$ & & $3.04^{c}$ & 2.18 & 4.27 & $2.39^{c}$ & 1.92 & 2.97 \\
\hline \multicolumn{8}{|l|}{ Gender } \\
\hline Male & Female & $0.59^{c}$ & 0.50 & 0.70 & $0.33^{c}$ & 0.30 & 0.37 \\
\hline \multicolumn{8}{|l|}{ Race } \\
\hline Black & White & $1.89^{c}$ & 1.41 & 2.54 & 1.15 & 0.97 & 1.37 \\
\hline American Indian/Alaska Native & & 1.11 & 0.44 & 2.83 & 1.24 & 0.67 & 2.31 \\
\hline Asian & & 1.22 & 0.80 & 1.85 & $0.50^{c}$ & 0.39 & 0.63 \\
\hline Non-Hawaiian/Pacific Islander & & $N A^{e}$ & $N A^{e}$ & $\mathrm{NA}^{\mathrm{e}}$ & 1.10 & 0.45 & 2.70 \\
\hline Multiple races & & I.II & 0.57 & 2.14 & 1.17 & 0.71 & 1.91 \\
\hline \multicolumn{8}{|l|}{ Ethnicity } \\
\hline Hispanics & Non-Hispanics & $0.6 \mathrm{I}^{\mathrm{d}}$ & 0.44 & 0.85 & $1.66^{c}$ & 1.43 & 1.93 \\
\hline \multicolumn{8}{|l|}{ Insurance } \\
\hline Public & Private & 0.91 & 0.66 & 1.27 & 0.81 & 0.67 & 0.98 \\
\hline Uninsured & & $0.30^{c}$ & 0.24 & 0.39 & $0.26^{c}$ & 0.23 & 0.30 \\
\hline \multicolumn{8}{|l|}{ Income (US\$) category } \\
\hline $20,000-34,999$ & $<20,000$ & 1.07 & 0.84 & 1.36 & 1.06 & 0.92 & 1.21 \\
\hline $35,000-54,999$ & & 1.18 & 0.89 & 1.56 & $1.50^{c}$ & 1.25 & 1.79 \\
\hline$>55,000$ & & $1.79 c$ & 1.34 & 2.39 & $1.91^{\mathrm{c}}$ & 1.57 & 2.34 \\
\hline \multicolumn{8}{|l|}{ Perceived health status } \\
\hline Very good & Excellent & 1.10 & 0.87 & 1.40 & 1.07 & 0.93 & 1.25 \\
\hline Good & & $1.6 \mathrm{I}^{\mathrm{d}}$ & 1.27 & 2.05 & $1.39^{c}$ & 1.18 & 1.63 \\
\hline Fair & & $1.8 \mathrm{I}^{\mathrm{d}}$ & 1.30 & 2.52 & $1.89^{c}$ & 1.50 & 2.38 \\
\hline Poor & & $3.08^{d}$ & 1.60 & 5.95 & $3.65^{c}$ & 2.57 & 5.20 \\
\hline
\end{tabular}

Notes: ${ }^{\mathrm{a}} \mathrm{C}$ statistic for cholesterol check up utilization model $=0.7 \mathrm{I} 6{ }^{\mathrm{b}} \mathrm{C}$ statistic for blood pressure check up utilization model $=0.772 ;{ }^{\mathrm{c}} \mathrm{P}<0.00 \mathrm{I}$, based on $\mathrm{W}$ ald $\mathrm{F}$ statistics $\mathrm{d} P<0.0 \mathrm{I}$, based on Wald $\mathrm{F}$ statistics; ${ }^{\mathrm{N} A}$, not applicable (due to insufficient cell size to run logistic regression).

likely to utilize preventive care services. Age is an associated risk factor for cardiovascular diseases, and the presence of existing conditions may also be among the causes for higher utilization amongst this population. ${ }^{20,21}$

Gender differences were also found to influence the use of preventive care services. Utilization levels were lower for both blood pressure and cholesterol amongst males. This lower utilization may be due to the difference in health behaviors that has been observed between males and females. ${ }^{22}$ Also, females might be utilizing preventive care more because it has been shown that woman are in fact at a greater risk for mortality from heart disease than males. ${ }^{23}$ A rather interesting race-related trend that was observed in our study was lower utilization of blood pressure screening by Asians. National reports have consistently shown that Asians are the group that has the lowest utilization of health care services. ${ }^{24}$ This may have also led to their lower utilization of preventive care services in this group. Another likely cause for this result may be the higher utilization of complementary and alternative medicines (CAM) amongst this population. Past studies have shown that CAM modalities such as herbal medicines are used by Asian Americans at rates almost three times higher than that of Whites. ${ }^{25}$ While other race differences were consistent amongst both services, Blacks were found to utilize cholesterol services at almost double the rate of Whites. Blacks generally are at a higher risk for cardiovascular diseases, and studies have shown that Blacks receive more counseling than Whites. ${ }^{26}$ For these reasons, it is possible that this group was aware of the threats of cardiovascular outcomes and therefore utilized the preventive care services more than Whites.

Income and insurance status continue to play a role in determining the utilization of preventive care services. As expected, people with lower income and the uninsured population had lower likelihood of utilizing preventive care services. High cost and lack of insurance have been identified as the most common causes for nonutilization of health care services. ${ }^{27}$ Low utilization, even in the presence of high utilization rates, is an issue that needs to be addressed, as the uninsured usually have poorer health outcomes compared with their insured counterparts. ${ }^{28}$ Furthermore, our result was in line with our hypothesis that people with higher perceived health status utilized the services less than people who considered their health status as poor. People who generally 
consider themselves in good health have been shown to make less use of primary care and specialty services. ${ }^{29,30}$ This study once again shows the inadequacy of utilization of health care services by people who perceive themselves to be healthy. It is necessary to inform them about the benefits of using these preventive care services for early detection of any abnormalities that can help them to maintain their good health.

Our analysis opens the scope for further research into the probable reasons for the disparities that were the focus of our study. A pertinent question that goes along with the use of preventive care is its impact on actual health care expenditures, which we did not assess in our study. Blood pressure checkup and cholesterol screening are simple and cheap services, especially considering the economic burden that cardiovascular complications pose. Future studies can examine whether utilization of these services actually helps save costs for the people who utilize them as per recommended guidelines. Primary health care providers often face a time crunch that prevents them from addressing all preventive care services for the patient. ${ }^{31}$ In such a scenario, highlighting preventive care utilization patterns amongst the general population will assist health care providers.

\section{Limitations}

Due to the patient self-reported nature of MEPS, the results are subjected to recall bias and other potential dataset-related errors. Recall bias may especially hinder the patients' ability to respond to questions where respondents are asked to recollect health-related events that happened within the large time frame of 5 years, as is the case of cholesterol screening utilization. Due to the retrospective and cross-sectional nature of the database, causal inference cannot be drawn and confounding factors may also affect the results. Also, the results are limited to 1 year of the MEPS database, limiting the ability to assess how consistent our results are over a longer period of time. Our analysis does, however, broaden the scope for further research into the probable reasons for the disparities which were mentioned in our study. A pertinent question that goes along with use of preventive care is its impact on actual health care expenditures, which we did not asses in our study. Blood pressure checkup and cholesterol screening are simple and cheap services, considering the economic burden that cardiovascular complications pose. Future studies should explore whether preventive care services actually help reduce costs for those people utilizing them as per recommended guidelines.

\section{Conclusion}

The study highlighted the lack of progress made in appropriate utilization of blood pressure checkup and cholesterol checkup services in the last decade. The study was also successful in identifying populations that show lower utilization of these services. Probing further for the causes of these disparities can help bring about policy changes that increase utilization of these services. This can serve as a first step for reducing the economic burden of cardiovascular diseases.

\section{Disclosure}

The authors report no conflicts of interest in this work.

\section{References}

1. National Commission on Prevention Priorities. Preventive Care: A National Profile on Use, Disparities, and Health Benefits. Washington, DC: Partnership for Prevention; 2007.

2. Marin MG, Zitter JN. Expenditures associated with preventive healthcare. Prev Med. 2004(39):856-862.

3. Nelson DE, Bland S, Powell-Griner E, et al. State trends in health risk factors and receipt of clinical preventive services among US. Adults during the 1990s. JAMA. 2002;287(20):2659-2667.

4. Mokdad AH, Marks JS, Stroup DF, Gerberding JL. Actual causes of death in the United States, 2000. JAMA. 2004;291(10):1238-1245.

5. American Heart Association. Cardiovascular Disease Statistics. Available from: http://www.americanheart.org/presenter.jhtml?identifier=4478. Accessed Aug 52010.

6. Evans CD, Eurich DT, Taylor JG, Blackburn DF. The Collaborative Cardiovascular Risk Reduction in Primary Care (CCARP) study. Pharmacotherapy. 2010;30(8):766-775.

7. Thom T, Haase N, Rosamond W, et al; American Heart Association Statistics Committee and Stroke Statistics Subcommittee. Heart disease and stroke statistics - 2006 update: a report from the American Heart Association Statistics Committee and Stroke Statistics Subcommittee. Circulation. 2006;113(6):e85-e151.

8. Trogdon JG, Finkelstein EA, Nwaise IA, Tangka FK, Orenstein D. The economic burden of chronic cardiovascular disease for major insurers. Health Promot Pract. 2007;8(3):234-242.

9. Pennant M, Davenport C, Bayliss S, Greenheld W, Marshall T, Hyde C. Community programs for the prevention of cardiovascular disease: a systematic review. Am J Epidemiol. 2010;172(5):501-516.

10. Stuart-Shor EM, Nannini A, Ostrem M, Russell GE, Mittleman MA. The prevalence of blood pressure and cholesterol monitoring in Boston among non-Hispanic blacks, Hispanics, and non-Hispanic whites. Ethn Dis. 2006;16(2):375-383.

11. Anderson G, Hussey PS. Comparing health system performance in OECD countries. Organization for Economic Cooperation and Development. Health Aff (Millwood). 2001;20(3):219-232.

12. Gold R, DeVoe J, Shah A, Chauvie S. Insurance continuity and receipt of diabetes preventive care in a network of federally qualified health centers. Med Care. 2009;47(4):431-439.

13. Collins KS, Hughes DL, Doty MM, Ives BL, Edwards JN, Tenney K. Diverse Communities, Common Concerns: Assessing Healthcare Quality for Minority Americans. New York, NY: The Commonwealth Fund; 2002.

14. Chobanian AV, Bakris GL, Black HR, et al. Seventh report of the Joint National Committee on Prevention, Detection, Evaluation, and Treatment of High Blood Pressure. Hypertension. 2003;42(6):1206-1252.

15. Third Report of the National Cholesterol Education Program (NCEP). Expert panel on detection, evaluation, and treatment of high blood cholesterol in adults (Adult treatment panel III) final report. Circulation. 2002;106(25):3143-3421. 
16. Partnership for Prevention. Preventive Care: A National Profile on Use, Disparities, and Health Benefits. Washington, DC: Partnership for Prevention; 2007.

17. Park MJ, Paul Mulye T, Adams SH, Brindis CD, Irwin CE Jr. The health status of young adults in the United States. J Adolesc Health. 2006;39(3):305-317.

18. Fortuna RJ, Robbins BW, Halterman JS. Ambulatory care among young adults in the United States. Ann Intern Med. 2009;151(6):379-385.

19. Turnbull F, Kengne AP, MacMahon S. Blood pressure and cardiovascular disease: tracing the steps from Framingham. Prog Cardiovasc Dis. 2010;53(1):39-44.

20. Kannel WB. Risk stratification in hypertension: new insights from the Framingham Study. Am J Hypertens. 2000;13(1 Pt 2): 3S-10S.

21. Rywik SL, Williams OD, Pajak A, et al. Incidence and correlates of hypertension in the Atherosclerosis Risk in Communities (ARIC) study and the Monitoring Trends and Determinants of Cardiovascular Disease (POL-MONICA) project. J Hypertens. 2000;18(8): 999-1006.

22. Courtenay WH. College men's health: an overview and a call to action. J Am Coll Health. 1998;46(6):279-290.

23. Malacrida R, Genoni M, Maggioni AP, et al. A comparison of the early outcome of acute myocardial infarction in women and men. The Third International Study of Infarct Survival Collaborative Group. N Engl J Med. 1998;338(1):8-14.
24. Agency for Healthcare Research and Quality. National Healthcare Disparities Report, 2005. Rockville, MD: Agency for Healthcare Research and Quality; 2005.

25. Mackenzie ER, Taylor L, Bloom BS, Hufford DJ, Johnson JC. Ethnic minority use of complementary and alternative medicine (CAM): a national probability survey of CAM utilizers. Altern Ther Health Med. 2003;9(4):50-56.

26. Lopez L, Cook EF, Horng MS, Hicks LS. Lifestyle modification counseling for hypertensive patients: results from the National Health and Nutrition Examination Survey 1999-2004. Am J Hypertens. 2009;22(3):325-331.

27. Devoe JE, Baez A, Angier H, Krois L, Edlund C, Carney PA. Insurance + access not equal health care: typology of barriers to health care access for low-income families. Ann Fam Med. 2007;5(6):511-518.

28. National Center for Health Statistics. Health, United States, 2009: With Special Feature On Medical Technology. Hyattsville, MD: National Center for Health Statistics; 2010.

29. Bellinger JD, Hassan RM, Rivers PA, Cheng Q, Williams E, Glover SH. Specialty care use in US patients with chronic diseases. Int J Environ Res Public Health. 2010;7(3):975-990.

30. Finkelstein MM. Hypertension, self-perceived health status and use of primary care services. CMAJ. 2000;162(1):45-46.

31. Pollak KI, Krause KM, Yarnall KS, Gradison M, Michener JL, Ostbye T. Estimated time spent on preventive services by primary care physicians. BMC Health Serv Res. 2008;8:245.
Risk Management and Healthcare Policy

\section{Publish your work in this journal}

Risk Management and Healthcare Policy is an international, peerreviewed, open access journal focusing on all aspects of public health, policy, and preventative measures to promote good health and improve morbidity and mortality in the population. The journal welcomes submitted papers covering original research, basic science, clinical \& epidemio-

\section{Dovepress}

logical studies, reviews and evaluations, guidelines, expert opinion and commentary, case reports and extended reports. The manuscript management system is completely online and includes a very quick and fair peerreview system, which is all easy to use. Visit http://www.dovepress.com/ testimonials.php to read real quotes from published authors. 